\title{
The Integration and Innovation of Hotel Management in the New Trend
}

\author{
Shuangfan Song \\ Hubei University of Science and Technology, Xianning, China
}

Keywords: New trend; Hotel management; Innovation and development; Integration and innovation

\begin{abstract}
Due to the continuous rectification and change of the market economy, the demand for hotel management is also rising. In face of the new form now, in order to be able to meet the current social and economic development needs of the hotel, it is important to deal with the previous management plan and the current situation to create a new hotel management model, and thus, promoting the all-round development of hotel. This paper mainly explores how the work of hotel management can be integrated and innovated under the new situation.
\end{abstract}

\section{Introduction}

Before the economic globalization, the hotel management mainly stayed in the service quality and the humanization of the facilities. The concrete performance was the internal management of the enterprise and the meticulous management within the enterprise, which led to the customer satisfaction to the enterprise. Outstanding business management allows businesses to get a higher rating in the surrounding areas. Under the new economic trend, people's incomes increase with the demand for a better quality of life. More and more people choose to travel this way of life. The development of tourism makes the hotel service industry further develop [1]. Under the tide of economic globalization, the original management mode is not suitable for the needs of today's development. Therefore, the enterprise must develop its external marketing strategy and enlarge its own enterprise. The new economic tide has led to a sharp increase in the demand of the hotel service industry. Driven by the interests, more and more people are devoted to the hotel service industry. Establishing your own brand among many companies is a requirement of success.

In this way, the hotel services not only customers, but also their own brand, which is the economic promotion of marketing, sales of their own brand at the same time, showing their services, corporate reputation and sales commitment. In the wave of new economy, we first need to establish our own brand, and secondly to consider the benefits [1]. A good brand needs a good corporate culture. In this way, the concept of self-development exists within the enterprise and provides the foundation for the future development of the MNC. In addition, the culture is closely related to the brand of the enterprise, and the enterprise without the culture will not have a great impact on the development of the small-scale enterprise. However, for the larger multinational enterprises, it is necessary to have a strong corporate culture and fine Management regulations. In terms of fine management, Europe and the United States have more mature ways of business management and can learn from them appropriately. Foreign enterprises have a clear division of labor from the leadership to the lowest level and the division of labor among various departments is clear, which has greatly enhanced the development of enterprises.

\section{Hotel management status quo}

\subsection{Hotel industry market situation}

With the rapid social development and the improvement of our country's status in the international environment, the domestic tourism industry has a good momentum of development. The internationalized and popular tourism market has basically reached maturity, and the tourism industry has a bright future for development and has promoted the further reform and innovation in the hotel industry. At this stage, the brand concept plays an important role in the development of the enterprise. Most of the listed hotels, in order to further enhance their core competitiveness, have made 
innovations towards innovation in brand management from self-support to reduce the importance of asset management in hotel management [1]. Compared to the star hotel, China's tourism industry has entered the stage to meet the needs of most people, economic hotel has a more broad development prospects, and gradually by all sectors of concern. Its advantage is to meet the general public, the price is easy to be accepted, and now free exercise, traveling by car and other forms of free play gradually increased. Therefore, the demand for economic hotels will increase accordingly.

\subsection{Hotel management problems}

1) Too weak a service functions by paying too much attention to the price. Most domestic hotels did not give enough attention to customer service, the price is not a key factor in hotel management, the hotel in order to have long-term development, and we must have the service-oriented philosophy. In the increasingly fierce market competition at this stage, reducing costs and improving efficiency are the main sources of hotel profits. However, most hotels only focus on infrastructure construction and minimize their expenditure [2]. This will only reduce the standards of hotel management services and thus resulting in the quality of service cannot meet the needs of customers, and ultimately not get healthy long-term development.

2) Hotel staff cooperation is not strong. Every employee should realize that the department is a "stage" of the hotel. Everyone is playing a specific role. To play this scene requires the collective cooperation of employees [2]. When busy with reception or leaving work due to special circumstances, other employees must be able to take the place of their job to make their guests happy.

3) Easy to ignore the building of enterprise culture. Hotel corporate culture is the hotel according to their own characteristics, in order to achieve a common endorsement of the objective for the survival and development of the hotel and set a value orientation. It is the organic unity of many contents including the values of the hotel, including spirit, concept, style, habit, code of conduct and so on. China's hotel industry did not pay enough attention to corporate culture and did not form the main corporate values [2]. Speaking from the degree of professional love, there is a big gap between China and the developed countries. Whether managers or ordinary employees, most of them lack of "job satisfaction", did not heart to the hotel as a career love, in the final analysis is the lack of corporate culture influence, there is no formation of the main values. 4. Lack of professional management personnel. In the traditional concept of people, the hotel business is not an iron rice bowl, which requires people to start from the bottom of the work, and the wage increase is less, let alone hires professional hotel management personnel.

\section{Hotel management integration innovation points}

\subsection{Hotel industry on technological innovation}

In the management and improvement of enterprises, the effect of hardware measures is more and more important. The impact of economic globalization is a huge challenge to the hotel industry. People are more and more demanding in the service industry. In order to meet the needs of consumers and satisfy the requirements of modern life, companies must make improvements in their own technology [1]. In the traditional hotel service industry, regionalization and high degree of commercialization, but the competition is not intense. Therefore, under the situation of the seller's market, many hotel industry's internal measures are not perfect, more individual hotels use improper means to snatch away tourists. The development of the hotel is not determined by the factors of enterprise personnel, enterprise system and facilities, of the economy, the new business model, the old business model has been unable to meet consumer demand [2]. The fierce competition among enterprises forces enterprises to need the business attitude of excellence. Under the guidance of such a fine concept, the enterprises are constantly improving and improving, laying a good foundation for the further improvement of the interests of the enterprises.

\subsection{Institutional Innovation in Hotel Management}

Economic restructuring and development of the business requirements continue to rise. In order to 
ensure the normal operation of the enterprise, the original system needs to be improved so that the operation of the enterprise meets the requirements of the new era. At the same time, the enterprise should adapt to the changing information environment while keeping pace with the progress of information [3]. The original knowledge of the old system cannot meet the current situation of development, the drawbacks gradually appear, innovative management departments should take appropriate preventive measures to reduce the old system of enterprise development. In the meantime, we must also constantly train the staff of enterprises so as to continuously upgrade their professional capabilities and knowledge reserves so as to continuously improve their soft power and enhance their work efficiency [3]. The conservative thinking of the old business model led to the lack of communication between the various working layers of the enterprise, reducing the efficiency of work. The new innovation mode circumvented this issue, increasing the chances for internal staff to learn and exchange with each other, bringing innovation to the enterprise huge benefit.

\section{Necessity of Innovative Hotel Management Innovation under the New Situation}

\subsection{Hotel management and external marketing integration}

In the hotel service, the main optimization goal is to fully meet all the needs of customers. With the continuous improvement and development of modern society, hotel service personnel need to meet many requirements of customers. Through the improvement of the hotel's internal facilities, according to the current social development needs and customer requirements for reform, this can help hotel management more complete. However, since such hotel facilities also need to be managed according to effective management measures, the internal management system and the use of equipment need to be exposed to the way of external marketing [3]. By means of marketing externally, consumers can fully and comprehensively understand the equipment in the hotel, and thus be able to attract consumers to spend.

\subsection{Hotel Information Brand building and external marketing integration}

In the current development of the new situation, the hotel's main economy comes from tourism tourists, the hotel can provide a comfortable place to rest when tourists are tired, and then can be physically and mentally relaxed, so the hotel's information supply can help Tourists looking for a certain goal. In order to enable tourists to find useful tourist information, we need the hotel to provide accurate and real information to enable tourists to find quality attractions for sightseeing, which requires the hotel's brand building, can be known and recognized by tourists; enabling visitors Learn more about the tourist information directions available in the hotel [4]. In short, for hotels, such information resources need to be through the hotel brand building and external marketing strategies to integrate, and thus be able to promote the hotel's management can be more humane, can enrich the hotel's management of new measures.

\subsection{Tourist culture and multi-faceted service integration}

In the present phenomenon of tourism appears, the hotel's cultural development needs to be fully improved. For example, tourists feel the elegance of the scenery, the hotel's cultural identity and the need to integrate the ecology of the customer's thought level, so that tourists can be fully relaxed [4]. Because of this hotel's cultural atmosphere can provide tourists with more quality management services, not only need to change the internal detailed management, but also for the hotel management system to improve. Therefore, the cultural characteristics of the hotel management can highlight its own hotel brand, visitors can get the best quality hotel management services for the hotel's future development to bring high-quality help.

\section{Hotel management integration of innovative measures}

\subsection{Cultural integration and innovation}

The hotel's culture can not only bring new cultural atmosphere for tourists, but also make the brand 
building of the hotel more reasonable and make the hotel's overall cultural atmosphere be fully improved. Many hotels now have a certain degree of cultural development, but only from the cultural taste of innovation can be seen that some hotels do not have deep-rooted cultural atmosphere, from this perspective we can see that the hotel's cultural innovation can be in line with the present the demand of social development is the main manifestation of the spirit of modern society. Therefore, it can be concluded that the brand's cultural endogenous needs to carry out reforms and innovations based on the current needs of social development and conduct a comprehensive reform of the traditional culture [5]. At the same time, it is necessary to integrate the cultural innovations of the talented people, comprehensively carry out the cultural conception from the top to the bottom, present the cultural levels, and conduct comprehensive innovation and reform through the people-oriented management approach, and use advanced cultural innovation technologies to create high-quality hotels Cultural brand, for the hotel's future development to bring help.

\subsection{Insiders and outsiders of innovation}

In the hotel management should be clear and clear management mechanism of personnel, and only such a comprehensive management system will be able to make the hotel's internal outsiders and atmosphere to be upgraded, and thus be able to make the innovation of talent can be fully demonstrated Out of hotel cohesion [5]. In the hotel management system to break through the previous system of norms, the formation of a unique form of talent management, through the promotion of planning, can enable people to actively promote, and thus be able to have a more excellent hotel services, to the current promotion Mechanism to develop a more excellent promotion system, so that employees work more meticulous, so as to form a good form of hotel management. By developing a more comprehensive promotion plan to ensure that grass-roots employees have the opportunity to implement their own talents, employees can be filled with passion, fighting spirit to complete the efficient service work, for the hotel can do its due diligence and give full play to their initiative.

\subsection{Introduce the concept of job cost management}

Activity-based cost management philosophy to change the past, the product as the core approach, it is homework as the core, the core of the cost of the cause, the results above, by tracking operations and real-time activities reflected in order to have an accurate prediction of the overall situation and grasp [6]. This new method not only applies to enterprises, but also conducive to the development of the hotel industry, to provide business managers with accurate and timely cost information to ensure the reliability and authority of their decision-making. In addition, it can help hoteliers to find ways to reduce hotel costs through operations, motivation analysis and other information, analyze and judge hotel's profit and loss status in a certain period of time, enhance book reviews of hotel management and enhance the hotel's position in international competition.

\subsection{Combine with local culture to establish its own characteristics}

After entering a new era, multinational corporations have accelerated the pace of development, which undoubtedly poses a serious challenge to the development of domestic brands. In the fierce competition in the market, local brands in the local development has the most important advantages, namely, location, people and, which not only contains the social and ethnic significance, but also to reflect the hotel's unique culture, national culture, hotel management innovation is a new type of thinking [6]. Therefore, the distinctive local culture brand has an important economic significance. Only by combining traditional Chinese culture with modern science and technology effectively and developing hotel brands with Chinese characteristics can we enhance the core competitiveness of China's hotel industry.

\subsection{Strengthen the hotel staff team building and system construction}

How to retain good employees is an issue that entrepreneurs must face and solve. It is important for entrepreneurs to create an atmosphere in which employees are willing to stay and work side by side with themselves. Initial venture capital is limited; the common and effective way is the boss's 
family management. Being an early-stage boss can quickly establish a relatively stable team in a short period of time if it can be a mentor to employees, a good friend in life, and caring for their own relatives like their relatives [7]. According to statistics, more than $90 \%$ of enterprises encounter the pain of flood of affection, ignoring the system construction and management. Although affection management can help enterprises to develop quickly and steadily in the early stage, it also has many drawbacks. For example, there may be contradictions between relatives and ordinary employees due to differences in treatment. If they are not handled well, the team will be divided, and relatives and staff It may also have a negative impact on the business philosophy and ideas, an obstacle to the development of enterprises [7]. Therefore, the proposed hotel companies in the business must be synchronized during the system construction, the system is not much, not fine, as long as practical and feasible.

\subsection{Innovative hotel management to meet customer needs}

Under the new trend, the individualized demand of customers plays an important role in the service industry, especially the hotel development, but most people have a wrong understanding of it. Customer personalized service is based on the different requirements of customers with different, unique, mobility, unexpected services, under normal circumstances the hotel cannot be an additional charge, mainly software and hardware, accessories and facilities, special catering services wait. If the hotel guests hold a banquet in the hotel, the hotel should be based on the level and characteristics of banquet personnel to prepare matching rooms, seating and so on [7]. The humanized service of the hotel can impress the guests and further improve the customer's secondary consumption rate. In the hotel restaurant, the design of a personalized menu is very important.

\section{Conclusions}

In order to make the management of the hotel smoother and to make the hotel develop more rapidly, it is necessary to carry out a comprehensive reform in response to the actual situation of the hotel. By integrating the hotel's marketing mode and internal culture, the hotel culture can be improved. In order to make the hotel in the market competition can have a foothold, but also need to train the hotel's internal talent, enrich the internal quality of the hotel, so that hotel management can be more perfect, and promote hotel development.

\section{References}

[1] Y.J. Ma, Integration and innovation of hotel management under the new trend, China Business, 2011, vol.2, pp.23-27.

[2] Ch. Y. Xue, Innovative Integration and Innovations in Hotel Management under the New Trend, University Education, 2014 vol.6, pp.12-15.

[3] J.T. Feng, Innovation and integration of hotel management under the new situation, China Business, 2015, vol. 3, pp.32-34.

[4] X.Y. Gao, On the new era of hotel management integration innovation thinking, management observation, 2015, vol.9, pp.76-79.

[5] M.T. Jia, Convergence and innovation of Hotel Management under the New Trend, China Business, 2011, vol.11, pp.46-48.

[6] Y.L. Chen, Hotel management under the new situation to achieve innovation, Journal of Heilongjiang Institute of Education, 2014, vol.4, pp.53-56.

[7] Cao Jun, Higher vocational hotel Managements innovative, University Education, 2015, vol.14, pp. 3-5. 